\title{
Editorial: COVID-19 (coronavirus disease): Impacts on motor behavior
}

\author{
FABIO A. BARBIERI' | JOSÉ A. BARELA² | NATALIA M. RINALDI³
}

1 São Paulo State University (UNESP), School of Science, Graduate Program in Movement Sciences, Department of Physical Education, Human Movement Research Laboratory (MOVI-LAB), Bauru, SP, Brazil.

2 Institute of Biosciences, São Paulo State University (UNESP), Rio Claro, SP, Brazil.

3 Federal University of Espírito Santo (Ufes), Vitória, ES, Brazil.

Correspondence to: Fabio Augusto Barbieri. Av. Eng. Luiz Edmundo Carrijo Coube, 14-01, Vargem Limpa. Bauru, SP CEP 17033-360. Phone + 55 14 $3103-9612$ email: fabio.barbieri@unesp.br

https://doi.org/10.20338/bjmb.v15i1.244

The COVID-2019 pandemic is a highly pathogenic viral infection that changed drastically daily life, including social distancing as one of the preventive measures. ${ }^{1}$ Million lives have been significantly altered, and a global, multi-level, and demanding stresscoping-adjustment process is ongoing. This Special Issue stimulates novel investigations and theoretical perspectives on how the COVID-19 pandemic is affecting motor behavior in children, middle-aged and people with the disease, such as diabetes, hypertension and neurological. It helps to understand the effects of the COVID-19 pandemic especially social distancing measures, on motor behavior and suggests effective strategies to manage motor behavior during the COVID-19 pandemic.

The changes in routine may impact motor behavior, requiring a flexible adaptation to new circumstances, which includes teleinterventions and remote physical education classes, exercise training adaptations, health care modifications, etc. Also, World Health Organization ${ }^{2}$ reported that the COVID-19 pandemic changes lifestyle to deal with isolation and quarantine, impairing sleep quality, increasing alcohol consumption, reducing physical activity and worsening dietary habit. All these changes impair motor behavior. Moreover, COVID-19 may have negative psychological and neurological effects, ${ }^{3}$ trigging off worsening in the motor performance.

Articles in the present Special issue discuss the impact and how to help people cope with and adjust to the critical situation and highlight the effects of the COVID-19 pandemic on engagement in sedentary behavior, motor and non-motor aspects and healthy condition (e.g., management of diseases). A rich combination of themes related to motor behavior during the COVID-19 pandemic is presented by five articles dedicated to this issue. First, two author's point of view articles open the debate on motor control and management of diseases (e.g., diabetes and hypertension) issues caused by the COVID19 pandemic $^{6,7}$. Pelicioni and collaborators 6 outline the neurological, mental health, and cardiorespiratory issues caused by the COVID-19 infection on motor control, especially on locomotion and balance control. The paper address how the combination of these issues affects human balance and locomotion, discussing the importance of physical activity strategies to further reduce the negative impacts caused by COVID-19 infection. The authors add some evidence that COVID-19 infection causes neurological impairments, 
such as in brain structure and function of thalamus and brainstem, affecting the planning and organization of movement outputs, including locomotion and balance. On the other hand, they highlight that physical exercise may combat mental and physical consequences due to the COVID-19 in order to manage the deficits caused by neurological, mental, cardiorespiratory issues, hospitalization, and physical inactivity. Marçal and $\mathrm{Ciolac}^{7}$ continue the debate of positive exercise effects on limitation/changes caused by COVID-19 pandemic, especially on chronic diseases. The authors suggest a decrease in physical activity levels and a rise in sedentary behavior during the COVID-19 pandemic, which may substantially increase the burden of non-communicable chronic diseases. Thus, they conclude that home-based training, which may have advantages, such as access, flexible scheduling and privacy, can combat and minimize physical inactivity, becoming a key and important aspect of public health maintenance.

Following on from these points of view, three experimental articles investigate the effects of exercise on motor and non-motor aspects, and engagement in sedentary behavior and physical activity level in different populations (i.e., children, midlife individuals and people with Parkinson's disease). Leite et al. ${ }^{8}$ analyze the engagement in playful activities and electronics use during COVID-19 social distancing among children. They are also interested in the impact of staying at home without attending school on physical activity level. Surprisingly, the authors show that children maintained playing time during COVID-19 social distancing, but they increased the time spent using electronic devices. These impacts seem to be due to the characteristics of the social distancing implemented in Brazil, which did not prohibit people from going out and thus never effectively restricted people's mobility.

Menuchi and colleagues ${ }^{9}$ examine changes in physical activity levels and leisure time in urban space during quarantine in midlife individuals. The findings expand the knowledge about the effects of quarantine in leisure domains, indicating that the total time spent on physical activities did not change during this period, but the midlife individuals reduced occupational and transport physical activity and an increased in domestic physical activities and sitting time on weekends. The results of this study are important to promote public health campaigns during the COVID-19 pandemic such as 'move more and sit less during the day, reducing the deleterious effects of inactivity imposed during social distancing.

Finally, Santinelli and collaborators ${ }^{10}$ investigate how synchronous and asynchronous remotely exercise during pandemic COVID-19 affect motor and non-motor symptoms during home confinement in people with Parkinson's disease. The authors interrogated electronically three groups of individuals with Parkinson's disease i) who are performing a live (synchronous) exercise during social distancing; ii) who are performing a recorded (asynchronous) exercise during social distancing, and iii) who are not performing exercise during social distancing. The study adds that stay active, through synchronous or asynchronous exercises, during COVID-19 pandemic lockdown is beneficial for motor and non-motor symptoms in people with Parkinson's disease. The article's findings indicate and encourage individuals with Parkinson's disease to engage in remote exercise classes during the COVID-19 pandemic to preserve or improve motor and non-motor symptoms.

The multiplicity of contents presented in this Special Issue highlights the changes caused by a restriction of the COVID-19 pandemic in our life, indicating that public politics should be implemented together to social distancing and restriction measures. Although it 
was not the focus of any study in this Special Issue, all of them are favorable of social distancing measure (especially lockdown) to reduces the impact of the COVID-19 pandemic on the Brazilian people health, but the findings of these studies show clearly that health measures such as exercise should be also implemented to promote healthy behavior. Also, it is important to mention that the studies in this Special Issue represent Brazilian people's behavior or view from the COVID-19 pandemic, which did not respect a strict lockdown or social distancing. ${ }^{4}$ This behavior of limited restriction or cautiously measure, the high number of cases and deaths (Brazil's numbers are only surpassed by the United States and India) ${ }^{5}$ and the low social responsibility of the Brazilian government and the general population may affect the findings of the studies in this Special Issue and should be interpreted cautiously. Possibly studies in other countries that faced a long lockdown period (e.g., European countries) with severe restrictions to mobility may show different effects reported in our Special Issue. As COVID-19 presents a neurological effect on infected people and a behavioral changed around the world, understanding motor behavior during the COVID-19 pandemic is emerging and essential. Therefore, this Special Issue expands the discussion about measures to deal with the negative effects of the COVID-19 pandemic.

\section{REFERENCES}

1. Hamid S, Mir MY, Rohela GK. Novel coronavirus disease (COVID-19): a pandemic (epidemiology, pathogenesis and potential therapeutics). New Microbes New Infect. 2020;35:100679. 10.1016/j.nmni.2020.100679

2. World Health Organization. COVID-19 and violence against women: what the health sector/system can do, 7 April 2020. Geneva PP - Geneva: World Health Organization; 2020.

3. Arora T, Grey I. Health behaviour changes during COVID-19 and the potential consequences: A mini-review. J Health Psychol. 2020;25(9):1155-63.

10.1177/1359105320937053

4. Marinho PRD, Cordeiro GM, Coelho HFC, Brandão SCS. Covid-19 in Brazil: A sad scenario. Cytokine Growth Factor Rev. 2021;58:51-4. 10.1016/j.cytogfr.2020.10.010

5. Lobo A de P, Cardoso-dos-Santos AC, Rocha MS, Pinheiro RS, Bremm JM, Macário EM, et al. COVID-19 epidemic in Brazil: Where are we at? Int J Infect Dis. 2020;97:382-5. 10.1016/j.jijid.2020.06.044

6. Pelicioni PHS, Santos AD, Tako KV, Santos PCR.COVID-19 and its impact on human motor control. BJMB. 2021;15(1):9-19. 110.20338/bjmb.v15i1.196

7. Marçal IR, Ciolac EG. The importance to promote physical activity during COVID-19 outbreak to control the worsening of old pandemics. BJMB. 2021:15(1):20-25. 10.20338/bjmb.v15i1.217

8. Leite MMV, Barela AMF, Barela JA. Playful activity remained constant while electronics use increased in children during social distancing amidst the COVID-19 outbreak: A Poá's pilot study. BJMB. 2021:15(1):26-33. 10.20338/bjmb.v15i1.238

9. Menuchi MRTP, Kruschewsky AB, Ohara D, Honda MO, Ávila MA, Stein PP, Araújo D. Physical activity and sedentary behaviour adaptability to COVID-19 social and mobility constraints: a follow up study in Ilhéus - Bahia/Brazil. BJMB. 2021:15(1): 34-45.

10.20338/bjmb.v15i1.212 
10. Santinelli FB, Simieli L, Costa EC, Martineli LN, Fen CH, Tardelli E, Okamoto E, Tanaka K, Barbieri FA. Synchronous and asynchronous remote exercise may improve motor and nonmotor symptoms in people with Parkinson's disease during the COVID-19 pandemic. BJMB. 2021:15(1): 46-59. 10.20338/bjmb.v15i1.236

Citation: Barbieri FA, Barela JA, Rinaldi NM. Editorial: COVID-19 (coronavirus disease): Impacts on motor behavior. BJMB. 2021:15(1):5-8.

Editors: Dr Fabio Augusto Barbieri - São Paulo State University (UNESP), Bauru, SP, Brazil; Dr José Angelo Barela São Paulo State University (UNESP), Rio Claro, SP, Brazil; Dr Natalia Madalena Rinaldi - Federal University of Espírito Santo (UFES), Vitória, ES, Brazil.

Copyright:@ 2021 Barbieri, Barela, Rinaldi and BJMB. This is an open-access article distributed under the terms of the Creative Commons Attribution-Non Commercial-No Derivatives 4.0 International License which permits unrestricted use, distribution, and reproduction in any medium, provided the original author and source are credited.

Funding: This research did not receive any specific grant from funding agencies in the public, commercial, or not-forprofit sectors.

Competing interests: The authors have declared that no competing interests exist.

DOI: https://doi.org/10.20338/bjmb.v15i1.244 